\title{
CO-PREVALENCE OF HUMAN PAPILLOMAVIRUS AND EPSTEIN BARR VIRUS IN HEALTHY BLOOD DONORS IN QATAR
}

$\underline{\text { Ishita Gupta }}{ }^{1}$, Ayesha Jabeen${ }^{1}$, Maria K. Smatti², Hamda A. Al-Thawadi ${ }^{1}$, Gheyath K. Nasrallah², Ali A. Sultan³, Moussa Alkhalaf $^{4}$, Semir Vranic ${ }^{1}$, Ala-Eddin Al Moustafa ${ }^{1,2,5}$

${ }^{1}$ College of Medicine, QU Health, Qatar University, Doha, Qatar; ${ }^{2}$ Biomedical Research Centre, Qatar University, Doha, Qatar, ${ }^{3}$ Weill Cornell MedicineQatar, Ar-Rayyan, Qatar, ${ }^{4}$ Faculty of Medicine, Kuwait University, Kuwait; ${ }^{5}$ Oncology Department, McGill University, Montreal, Quebec, Canada

BACKGROUND

Human papillomaviruses (HPVs) and Epstein-Barr virus (EBV) are human oncoviruses that can co-exist together. HPV DNA can be present in circulating blood, including peripheral blood mononuclear cells, sera, plasma, and arterial cord blood. On the other hand, human herpesvirus 4, commonly known as EBV is a DNA lymphotropic herpesvirus that is responsible for causing infectious mononucleosis.

Co-presence of high-risk HPVs and EBV mRNA in cervical, breast as well as oral cancers, is indicative of patients that are at a higher risk for developing metastases. The objective of this study is to establish whether HPV and EBV DNA are present in the blood of healthy individuals in the middle east region, more specifically in Qatar.
MATERIALS AND METHODS

DNA extracted from the buffy coat of 385 healthy blood donors were examined for the presence of EBV and low- and high-risk HPVs.

Five micrograms of purified genomic DNA (Qiagen GmbH, Hilden, Germany) from each sample was analyzed for EBV and HPV by PCR using specific primers for LMP1 as well as low (6 and 11) and high-risk HPV types $(16,18,31,33,35,39,45,51,52$, and 58 ), while, primers for GAPDH gene were used as an internal control.

\section{RESULTS}

Table 1. Demographic Data

\begin{tabular}{|c|c|c|}
\hline & $\begin{array}{c}\text { EBV (+) } \\
(235)\end{array}$ & $\begin{array}{c}\text { EBV (-) } \\
(150)\end{array}$ \\
\hline Category & Total No. (\%) & Total No. (\%) \\
\hline & \multicolumn{2}{|c|}{ Nationality \& Gender } \\
\hline Qatari & $102(43.4 \%)$ & $28(18.66 \%)$ \\
\hline Male & 101 & 27 \\
\hline Female & 1 & 1 \\
\hline Non-Qatari & $133(56.5 \%)$ & $122(81.33 \%)$ \\
\hline Male & 131 & 119 \\
\hline \multirow[t]{2}{*}{ Female } & 2 & 3 \\
\hline & \multicolumn{2}{|c|}{ Age Group } \\
\hline $20-39$ & $52(22.12 \%)$ & $46(30.66 \%)$ \\
\hline $30-39$ & $95(40.4 \%)$ & $63(42 \%)$ \\
\hline $40-49$ & $60(25.5 \%)$ & $34(22.66 \%)$ \\
\hline $50-59$ & $28(11.91 \%)$ & $7(4.66 \%)$ \\
\hline
\end{tabular}

Table 2. Prevalence of low- and high-risk HPVs in healthy blood donors

\begin{tabular}{|c|c|c|c|c|c|c|c|c|c|c|c|c|}
\hline \multirow{2}{*}{ Samples } & \multicolumn{10}{l|}{$\begin{array}{l}\text { No. of } \\
\text { Cases }\end{array}$} & \multicolumn{10}{|c|}{ HPV Types (\%) } \\
\cline { 3 - 13 } & $\mathbf{6}$ & $\mathbf{1 1}$ & $\mathbf{1 6}$ & $\mathbf{1 8}$ & $\mathbf{3 1}$ & $\mathbf{3 3}$ & $\mathbf{3 5}$ & $\mathbf{4 5}$ & $\mathbf{5 1}$ & $\mathbf{5 2}$ & $\mathbf{5 6}$ \\
\hline $\begin{array}{c}\text { EBV } \\
\mathbf{( + )}\end{array}$ & $\mathbf{2 3 5}$ & 41.3 & 45.5 & 35.7 & 34.5 & 39.6 & 4.6 & 35.3 & 30.6 & 36.2 & 37.9 & 27.7 \\
\hline $\begin{array}{c}\text { EBV } \\
\mathbf{( - )}\end{array}$ & $\mathbf{1 5 0}$ & 76 & 63.3 & 41.3 & 38.6 & 76 & 0 & 61.3 & 56.6 & 68 & 66.7 & 22.6 \\
\hline Total & $\mathbf{3 8 5}$ & $\mathbf{5 4 . 8}$ & $\mathbf{5 2 . 5}$ & $\mathbf{3 7 . 9}$ & $\mathbf{3 6 . 1}$ & $\mathbf{5 3 . 8}$ & $\mathbf{2 . 8}$ & $\mathbf{4 5 . 4}$ & $\mathbf{4 0 . 7}$ & $\mathbf{4 8 . 6}$ & 49.1 & $\mathbf{2 5 . 7}$ \\
\hline
\end{tabular}

Table 3. Association between HPV-subtypes and the studied populations (Qatari vs. Non-Qatari)

\begin{tabular}{|c|c|c|c|c|}
\hline \multirow{2}{*}{ Samples } & \multicolumn{5}{|c|}{ QATARIS v/s NON-QATARIS } \\
\cline { 2 - 5 } & $\mathbf{5 2}$ & $\mathbf{5 6}$ & $\mathbf{6 6}$ & $\mathbf{6 8}$ \\
\hline Qataris (102) & 47 & 37.2 & 39.2 & 19.6 \\
\hline $\begin{array}{c}\text { Non-Qataris } \\
\text { (133) }\end{array}$ & 30.8 & 24.8 & 26.3 & 32.3 \\
\hline $\boldsymbol{p}$-value & $\mathbf{0 . 0 2 2 *}$ & $\mathbf{0 . 0 3 4 *}$ & $\mathbf{0 . 0 3 5 5 ^ { * }}$ & $\mathbf{0 . 0 2 9 *}$ \\
\hline
\end{tabular}

\section{CONCLUSIONS}

In this study, we demonstrated for the first time that HPVs and EBV are commonly co-present in healthy blood donors in Qatar. We found that 55\% and 61\% of the samples were HPVs and EBV positive, respectively. Co-presence of both high-risk HPVs and EBV was seen in $40 \%$ of the samples. 